\title{
A proposed reconciliation of conservative and liberal approaches to instructional design
}

\author{
Philip R. Wallace \\ Defence Force Fellow \\ Curtin University of Technology
}

\begin{abstract}
The conservative approach to instructional design assumes training can be based upon general models of learning and an analysis of the skill. The liberal approach assumes students need to develop individually appropriate strategies for skill performance. The reconciliation of these two approaches is proposed through the organising concept of 'transfer of training'. Conservative approaches best support transfer to anticipated contexts. Liberal approaches best support transfer to unanticipated contexts. A combination of both approaches may lead to safe and efficient performance in defined situations as well as the flexibility to cope with novel situations.
\end{abstract}

The recent article by Jim Strain and Alistair Inglis in this Journal (1990) raised the fundamental, but rarely discussed, issue of the nature of instructional design. Their interesting explanation of the genesis of Victoria College's Graduate Diploma in Instructional Design and Technology suggested that instructional design "...primarily focuses on how learners interact with and encode different instructional materials. It is concerned with the structural properties of these materials and how these structural properties can facilitate memorisation, retrieval, transfer and learning". (p.8) Consequently, the new Graduate Diploma will most likely involve 'systems approaches', presumably with an analysis and decomposition of the skills to be learnt leading to the selection of media and methods. 
This rigorous and logical treatment of instructional design within a tertiary course devoted to the graduation of professional trainers, as opposed to an optional subject in a human resource development course, is most welcome. Furthermore, the instruction of job-related skills for adults is qualitatively different to primary and secondary school education and, therefore, requires professional skills different to those addressed within conventional education courses.

The previous Graduate Diploma of Educational Technology, of which I am a graduate, valiantly attempted to meet the needs of both professional trainers and school teachers. Consequently there was a mixture of both systematic and content-independent instructional design models. While undertaking this course, I had some difficulty understanding the relevance of liberal' theories of learning, such as Carl Rogers' Humanist approach, to the practice of instructional design for job-related skills. My grounding in military technical and pilot training suggested to me that systematic approaches were uniquely appropriate, however experience of several successful training courses which do not subscribe to the 'systems' paradigm has led me to re-assess my position.

A 'systems approach' alone does not suggest that 'adventure training' will improve the job performance of managers, but anecdotal evidence indicates that it does. A 'systems approach' would prescribe the practice of every inflight procedure until competence is demonstrated by pilots undergoing refresher training, but none of the highly effective RAAF cockpit simulator programs adopt such an approach. How, then, can the evidence both for and against the modern 'systems' paradigm be explained? I believe the answer lies in an examination of the philosophy of learning which is common to both training and education.

\section{Philosophical foundations of learning theory}

Recorded debate on the process of learning and how it should be fostered can be traced back to the classical scholars, most notably Plato and Aristotle. Their thoughts on how education could be used to improve society raised the issues of: the roles of learners and teachers, and the relationship between thought and the real world. While a detailed analysis of their works is beyond the scope of this paper, a summary of some of their main contentions does provide an insight into the foundations of modern instructional thought.

In their book on significant innovations in Western educational thought, Bowen and Hobson (1974, p.14) describe the following characteristics of the 'conservative' model of education, as passed down from Plato and Aristotle: 
1. "... the authority of the teacher is stressed and his role is seen as one of instilling in his pupils a required body of set subject matter."

2. "Little attention is paid to individual differences or children's interests."

3. "What goes on within (the school) is seen primarily as a preparation for the future rather than an enrichment of the present."

4. "The basic stress is on the knowledge to be acquired and it is this that determines the aims; notions such as development of potentialities or self-realisation being largely ignored."

This Conservative model with its presumption of knowledge being a set of derivable truths, independent of human existence, and the acquisition of this knowledge being preparation for future duties bears striking resemblance to modern systematic approaches to training design. The knowledge to be learnt is determined and instruction to teach this is planned; while individual differences between learners may exist these will not alter the knowledge under study. Moreover, there is little point in students 'exploring' content because the learning objective will not change and their exists dangers of unstructured learning leading to confusion and inefficiencies.

Plato and Aristotle differed over their view of the learner/teacher relationship within the Conservative model. Plato held that knowledge was innate and likened the task of the teacher with that of a midwife: "Those who frequent my company at first appear, some of them, quite unintelligent; but, as we go further with our discussions, all who are favoured by heaven make progress at a rate that seems surprising to others as well as to themselves, although it is clear that they have never learned anything from me; the many admirable truths they bring to birth have been discovered by themselves from within. But the delivery is heaven's work and mine." (Bowen \& Hobson, p.32)

Aristotle disagreed with Plato's notion of knowledge being innate. Aristotle believed learners possessed a sort of mental void which could be filled with knowledge passed on by teachers: "... mental capacities neither exist in clearly determined form from birth nor are derived from other higher capacities. In fact they originate in sense perception. The procedure is something like this: imagine that a rout has taken place on a field of battle; then one man makes a stand followed by another and another until the original formation is restored. The soul is so constituted that it behaves in a similar kind of way." (Bowen \& Hobson, p91) This does not imply that learners should be 'handfed', but that through 'sense perception' they can be led to form true knowledge.

So, the Conservative model accommodates differing views of teaching styles, but is inseparably bound to the notion of knowledge being definable without consideration of the individual learner and, therefore, being able to be specified ahead of learning taking place. Furthermore, 
knowledge is defined from absolute truths and, through application, will enable learners to competently carry out their future roles in society. The fundamental concept of there existing a definable set of knowledge necessary for proper performance of one's role in society is the basis of disagreement between the Conservative and Liberal models of education.

The first recorded challenges to the Conservative model appear to have been made by Rousseau, particularly in his description of the education of Emile in the novel of that name. In Emile, Rousseau argued that learning should be centred on the learner's needs, not on content selected by someone else. (Bowen \& Hobson, p.124) Furthermore, he advocated that learning of the sciences should take place through discovery and problemsolving, so that learning came from observation and experience. (Bowen \& Hobson, p.127)

Despite Rousseau's writings in the eighteenth century, education continued to focus on classical studies well into the twentieth century. A comprehensive rejection of the Conservative model was arguably first put forward by John Dewey in his book Democracy and Education, published in 1916. At the time of publication, the contemporary view was that the mind possessed certain faculties which could be exercised through the rote learning of facts from subjects such as Latin and geometry; this was known as 'the doctrine of formal discipline'.

Dewey rejected this doctrine and argued that learners should be encouraged to "... seek, enquire, explore..." so that they will be able to "... react to new situations with concern, flexibility and curiosity." (Bowen \& Hobson, p.169) The implication of this 'liberal' approach was that a set body of knowledge for study, which car. be defined independently of the learner, does not exist; the goal of education is not to enable students to recall certain facts or explain specific phenomena, but to develop each individual's ability to cope with new situations and resolve problems.

Modern instructional design aims to facilitate a learning process whereby agreed outcomes will be achieved. Application of the Conservative model of education to this aim sees required knowledge being defined from specified goals and appropriate instruction planned. Application of the Liberal model sees opportunities for inquiry, appropriate to the content domain, being offered through challenging and individually relevant learning environments.

Discussion so far has been of a philosophical nature and indicated that the Conservative and Liberal approaches to instructional design are each based upon defensible notions of how individuals may be best prepared for future tasks. The recent development of these two schools of thought will now be reviewed so that central assertions and practices may be explicitly stated. 
The conservative approach to instructional design

The goal directed nature of Behaviourism leads this school of psychology to be the one most readily identified with the Conservative approach to instructional design. The term 'Behaviourism' was coined by John B. Watson to give a name to his theory that all human behaviour was ruled by habit. (Watson cited in Sahakian, 1970, p.34) Watson's work came at a time when psychology was in its infancy and wracked by disagreement over the reasons behind behaviour. Anderson $(1980$, p.9) suggests that studies into subconscious motivations for action, predominantly in Europe, had become clouded by different laboratories reaching different conclusions because of the introspective and subjective nature of their inquiry, thus the time was ripe fore fresh and objective approach to the issue. However, Anderson also points out that this postponed research into cognitive psychology for about 40 years.

Theories of learning which became associated with Behaviourism include: Respondent Conditioning, Reinforcement Theories, Drive Reduction Theories and Operant Conditioning. Each of these provides for modification of learner behaviour, to some predetermined goal, through control over the environment. Often the research base for these theories employed laboratory experiments using animals, especially mice. Such an approach is consistent with the Behaviourist view that behaviour can be determined by external influences alone; the use of 'infrahumans' reduced the problem of eliminating confounding variables such as competing reinforcers. The numerous experiments conducted supported the Behaviourist theories which were sometimes summarised into principles which could be applied to the design of instruction, eg Thorndike's Laws of Readiness and Effect.

Behaviourism flourished in the first half of the twentieth century and led to the conservative approach to instructional design becoming firmly ensconced. However, a powerful criticism of Behaviouristic principles is that they have not been shown to be applicable to human training situations. (Lane, 1987) The argument here is not with the validity of the experiments undertaken in the past, but their relevance to human learning, in general, and the instruction of higher order cognitive functions, in particular.

In defence against this criticism, it must be noted that Behaviouristic theories have been successfully applied to human learning, the more recent and impressive work has been in the field of Skinner's Operant Conditioning. Skinner has proved that the phenomenon of operant conditioning does exist with humans and argues that we should control this process rather than let it proceed in an uncontrolled manner. (Skinner cited in Bowen \& Hobson, 1974, p.294) One of Skinner's most important contributions to the debate on instruction was the 'teaching machine'; this 
hypothetical device was intended to provide learners with carefully stepped instruction and feedback in accordance with the principles of operant conditioning. Unfortunately, Skinner's 'teaching machine' has been misused by some working in the field of computer-based training and this may have contributed to the concept's apparent decline in popularity. An example of the misuse of the 'teaching machine' concept is the use of multi-choice questions which invite recognition of the correct answer; Skinner was adamant that learners must recall, not recognise, information for it to be bully 'emitted' . (Skinner cited in Sahakian, 1970, p.149)

The difficulties encountered in employing Behaviouristic principles led to a renewed interest in the internal process of learning. This did not signal a departure from the Conservative approach; the assumption still being that tasks to be performed could be broken down into constituent components which must be mastered by learners. The new challenge was to determine how skills were cognitively represented so that appropriate instructional methods could be employed. Lane (1987) has also argued that an understanding of the cognitive process of learning is necessary for skills to be integrated into overall job performance, for example, without antagonistic effects on other pre-existing skills. Consequently, the last thirty years have seen much research into the application of Cognitivism to instruction; Gagne \& Dick (Cited in Lane, 1987), in a review of instructional technology, have even concluded that the field is now synonymous with that of cognitive psychology.

While conditioning theories enjoyed almost unrivalled popularity within the USA during the early part of the century, the same was not the case in Europe where much interest was being shown in psychoanalytic and Gestalt psychology. The American Edward Chace Tolman, who was influenced by Gestalt psychology during studies in Germany, was not content that conditioning and reinforcement adequately explained all learning. He proposed that purpose and cognition played an important part in determining behaviour and established the theory of 'Sign Learning', which he described as 'purposive behaviourism'. (Tolman cited in Sahakian, 1970, p.332) Tolman's major work 'Purposive Behaviourism in Animals and Men' was published in 1932 and led a revision of the role of cognition in learning theories.

Fitts (1964), in a discussion of perceptual-motor skill learning, summarised research into cognitive processes to provide a lucid three-phase account of skill learning. He suggested that the 'Early Phase' of skill learning was brief and devoted to the establishment of a 'cognitive set'. Fitts defines 'cognitive set' as referring to "... preparation in advance for the probabilities or contingencies characterising a given situation." (Fitts, 1964, p.270) During the 'Intermediate Phase' associations are formed, responses to cues are learnt and the cognitive set is developed. During the 'Late 
Phase' performance continues to improve over a long period of time with any 'plateau effect' being caused by equipment or motivational factors.

Fitts' discussion supplements, rather than contradicts, the Behaviourist learning theories. He suggests that the effect of 'cognitive sets' is to complement, not replace, stimulus-response association; the main achievement being a better understanding of the learning of incoherent tasks, that is those that do not possess a clear spatial or temporal pattern upon which stimulus-response associations can be formed. With regard to cognitive set learning and skill performance, Fitts concludes: "...(a) cognitive sets develop very slowly, and tend to generalise over many classes of similar situations; (b) however, once established they can be "called up" in a matter of about a second or less by an appropriate cue; (c) elicitation and utilisation of cognitive sets is often facilitated by the availability of verbal labels for use as cues although such labels are not necessary." (Fitts, 1964, p.276)

Albert Bandura also argued that conditioning and reinforcement are cognitively mediated. He proposed a four stage learning process based on behaviour modification through observation and imitation. Bandura's 'Social Learning Theory' or 'Modelling Theory' comprises: Attention, Retention, Reproduction, and Motivation. (Bandura cited in Sahakian, 1970) Despite the marked departure from early styles of Behaviourism, Bandura's work still implies that the means of carrying out a task can be defined for learners rather than learners defining this themselves, as a Liberal approach would allow. A particularly interesting aspect of Bandura's theory is the importance given to learner symbolic coding and rehearsal of the skill, these cognitive processes are ones which may be readily facilitated through instructional means such as simulation.

One of the most elaborate learning theories based upon internal representation of knowledge is that proposed by John R. Anderson. In 1982, Anderson published a paper summarising his refinement of the cognitive theories expressed earlier by Fitts (1964). Anderson's most significant contribution was his account of the use of 'productions', cognitive mechanisms which triggered an action once certain conditions are met. Anderson's rigorous approach provided powerful explanations of a range of observed learning phenomena including: rate of performance improvement with experience, reduced attention to task with increasing proficiency, and increasing availability of working memory with increasing skill proficiency.

Anderson adopted a three stage learning theory, similar to that of Fitts, but labelled the stages: Declarative Knowledge, Knowledge Compilation, and Procedural Knowledge. He suggested that the acquisition of cognitive skills initially involved the application of interpretive productions to information about the skill, ie declarative knowledge. Using an analogy of 
computer software development, Anderson likened this first stage with the use of an interpreter to run a program. With practice, new productions are formed which perform skill components without the need for conscious interpretation, Anderson likened this to the compiling of computer programs so that they can be run without an interpreter. Eventually, the skill becomes based upon procedural knowledge, that is a set of productions which allow skill performance with minimal conscious processing of information and minimal use of working memory.

Anderson's use of 'interpretive productions' to account for the performance of entirely new skills was innovative, but still did not adequately explain how domain-specific productions eventually arose. In a later paper, Anderson (1985) addressed this issue by suggesting that the use of interpretive productions revealed the hierarchical structure of goals peculiar to a domain and that this enabled knowledge to be compiled within an appropriate problem solving framework. The resulting framework of domain-specific productions is similar to ideas of hierarchical schema characterising specific skill domains (Glencross, 1976) and raises the possibility that such hierarchies can be revealed through task analysis and then used as a basis for instruction.

Anderson draws very few implications for instructional design, his theory is intended to be descriptive rather than prescriptive. Nevertheless, his work reflects a Conservative approach by implying that certain procedures will be better than others and, given adequate opportunity for 'generalisation', 'discrimination', and 'strengthening' these will eventually be established as cognitive productions. (Anderson, 1982)

The difference between the fields of cognitive psychology and instructional design is important to note; the former studies the processes of thought while the latter provides answers as to how individuals may most efficiently acquire a defined skill. While the two fields are certainly allied they are not one and the same. A review of the implications of cognitive theory for instructional design, by Bonner (1988), has suggested that "...cognitive psychologists and instructional designers do not understand each other very well" (p.12) and that the results of cognitive research should be carefully analysed for applications in instruction.

Bonner suggests four types of cognitive skill which should be considered during instructional design: declarative knowledge, procedural knowledge, problem solving and metacognition. The first two account for how information about a skill is mentally represented and have already been discussed. Bonner argues that problem-solving and metacognition are higher-order skills "... learned most effectively in the context of actually solving problems in a particular domain ..." (Bonner, 1988, p.5) and that metacognition, "...the techniques one uses to monitor oneself while solving 
problems, and the strategies one uses to learn" (p.4) is an activity especially overlooked in conventional instruction.

Apart from Bonner's discussion of metacognition, which is wholly dependent upon the individual learner, she conveys the idea that cognitive theory supports a Conservative approach to instructional design. This interpretation is strengthened by her description of how 'cognitive task analyses' differ from 'traditional task analyses' by identification of the cognitive skills required to perform a task; the inference being that there still exists a process of analysis to determine required knowledge, or other attributes, and that this process is independent of the individual learner.

While there are many other theorists who have provided valuable contributions to the Conservative approach (eg Reigeluth's Elaboration Theory, Merrill's Component Display Theory, Shiffrin \& Schneider's Information Processing Theory), the general nature of the field is reflected in the work of those already discussed.

\section{The liberal approach to instructional design}

The Liberal approach to education advocated by Dewey is arguably applicable to the instruction of job-related skills. The ability to "... react to new situations with concern, flexibility and curiosity." (Dewey cited in Bowen \& Hobson, 1974, p.169) may be invaluable in coping with unusual and difficult skill circumstances. There are several major theories of learning which are consistent with Dewey's thesis, these include Rogers' Freedom to Learn theory and Maslow's Third Force Psychology theory. Liberal approaches are characterised by a focus on the development of internal processes such as self regulation of problem-solving techniques, this particular process is a product of metacognition.

As mentioned above, metacognition has been defined as "the techniques one uses to monitor oneself while solving problems, and the strategies one uses to learn." (Bonner, 1988, p.4) Assuming that these techniques and strategies are independent of skill domain, the development of metacognitive ability in one area should transfer to other skill areas. Proponents of 'lateral thinking', such as Edward De Bono (1985), advocate self-developmental activities based upon the assumption that such transfer does occur. Such a thesis implies that the design of instruction should derive from individual learner characteristics rather than an analysis of the content domain.

The development of metacognitive skills in two separate British industrial training situations has been studied by Pearn and Downs (1989). They employed a program called Developing Skilled Learners (DSL) to assist in the re-training of staff within ICI's Agricultural Division and a major oil company's manufacturing and packaging plant. They reported success in 
both cases, at ICI "...the development of skilled learners was stitched firmly into the prevailing culture of facilitating and fostering meaningful change" and "The ideas had spread beyond the division and had been applied in local schools, church groups and in the trainer's own homes". While at the manufacturing and packaging plant the management believed that "...developing skilled learners during the induction, and designing the complex technical training according to DSL principles, was a major factor in helping create the new culture".

In an article on learning strategies and educational technology, Jonassen (1985) suggests that metacognitive strategies are only one of a number of issues to be addressed. He proposes that learning strategies also include: information-processing strategies, study strategies and support (ie motivational) strategies. Jonassen argues that learning strategies will become the most important concept in the field of educational technology and provides justification by describing an evolutionary process from device-cantered instruction to behaviour-centred instruction to instruction based on internal learner processes, hence learning strategies. (p.28)

The development of learning strategies is prominent in many training courses that might otherwise be considered Conservative. Recruits to the military generally undertake service indoctrination courses prior to commencing their trade or professional studies; military trainers argue that this provides students with good preparation for whatever course they are to undertake.

A striking example of pre-course learner development was personally observed during a visit to the Royal Swedish Air Force's pilot training unit at Ljungbyhed in 1987. RSwAF trainee pilots participate in a two week program combining lessons on the psychology of learning with field exercises prior to commencing their flying training. The field exercises are intended to introduce staff in a challenging, but cooperative, environment, while the psychology lessons are intended to enable students to learn efficiently during their subsequent training. One senior flying instructor described the role of staff as 'mirrors' so that students can see their deficiencies and decide upon remedies themselves. Notably, the RSwAF has one of the lowest failure rates in pilot training of any country (approximately $5 \%$ ), although the Swedes also conduct an extremely rigorous selection process which must be taken into account with several other unique training practices.

Pilot training is an area which has stubbornly resisted total adoption of the Conservative approach to instructional design. While there have been major efforts to apply a systematic approach to this field (Miller, Swink \& McKenzie, 1978) arguments such as 'this type of skill is different to others, it can't be broken down into a list' have prevailed. However, as early as 
1974, theoretical support for such arguments, and therefore a Liberal approach, was proposed by a researcher with the USAF Human Resources Laboratory, Edward E. Eddowes. Eddowes examined the way in which pilot training was conducted from a Piagetian perspective while also borrowing concepts from Bruner's Spiral Curriculum. Eddowes suggested that early pilot training was a process of increasing ability to discriminate errors in one's own performance. As learners gained more flying time they could detect finer details of performance errors and, in this way, were always competing with their last performance, in a similar way to an athlete.

In 1977 another USAF researcher, Gary A. Klein, suggested that complex skills cannot be adequately broken down into discrete steps. He described the analytical-systematic model as 'molecular' and suggested that a holistic approach was more appropriate in certain circumstances, especially when the goal was to develop highest possible proficiency with allocated resources rather than minimum acceptable proficiency. Klein suggested that novices view skills from a different perspective to experts and that an important learning process is the shift in perspective that must occur; the mechanics of this shift cannot be prescribed, it depends upon how individuals use imagery and insight to their own benefit. Klein's proposals are similar to another major Liberal approach that has emerged from cognitive psychology: Constructivism.

In a paper on the Constructivist view of media and technology, Catherine Twomey Fosnot suggested "Reality is acted on, transformed, and organised in relation to the learner's schemes, not simply selectively processed. New understandings are seen as invented constructions, rather than simple discoveries..." (1984, p.196) Learners are seen as 'constructing' knowledge within the world as they perceive it, this occurs through conflict resolution and contemplation of the broad implications of perceptions. Fosnot finally suggests that in Constructivist learning "... the technology of education aims at diagnosing the learner's structures and schemes, provides open-ended materials as a testing ground for the learner, and interjects appropriate contradictions" (p.203). Thereby suggesting that instructional design should focus on catering for individual learner characteristics and not force learning along a sequential, content-based and cumulative process.

Mainstream Liberal approaches to instructional design appear to have evolved from well-researched aspects of cognitive psychology. However, many more radical approaches are apparent through a review of the daily mass-media commercials for programs which claim to increase 'mind power'. In general, these radical approaches may be classified as Liberal although rigorous empirical evidence to support them, or a clear basis in cognitive psychology, may be difficult to locate. While some of these radical approaches may offer valuable contributions to our understanding 
of the learning process, others are simply 'pop psychology' with the potential to bring discredit upon the instructional design profession.

\section{Transfer of training}

The studies reviewed above indicate that both Conservative and Liberal approaches can be successfully employed. The instructional design issue, therefore, is not which of these approaches is correct and which is wrong, but when is the application of one more efficient than application of the other. The answer to this problem may be reasoned from the philosophies underlying each approach.

The Conservative approach assumes that the skill to be acquired may be dissected into discrete elements, instruction conducted to cumulatively teach these elements and, consequently, skilled performance be demonstrated by the learner. This process can only proceed if the skill can be precisely defined, that is in terms of anticipated conditions and standards. Otherwise, accurate description of the skill elements would not be possible. In relative terms, transfer of a skill from an instructional environment to one where the conditions have been anticipated during instruction has been defined as 'near transfer of training'. (Royer cited in Clark \& Voogel, 1985, p.114)

The transfer of a skill from an instructional environment to one where the conditions have not been addressed during instruction may, on the other hand, be considered 'far transfer of training'. (Royer cited in Clark \& Voogel, 1985, p.114) This second case is the antithesis of the first; since the operational context has not been anticipated the skill elements are unknown and, therefore, undefinable. In such circumstances, instruction must prepare the learner to adapt previously acquired procedures and create appropriate solutions in situ; this focus on the learner is the philosophical basis of the Liberal approach.

Consequently, situations requiring application of a skill in anticipated circumstances would seem to warrant a Conservative approach to instructional design. Conversely, situations requiring application of a skill in unanticipated situations would seem to warrant a Liberal approach to instructional design.

At this point a consideration of the reality of job-related training is worthwhile. One of the prime reasons for employing humans to perform tasks, rather than machines, is their adaptiveness and flexibility. While skills must often be performed under known conditions and to specified standards, especially for safety certification, graduates are generally expected to be able to apply 'commonsense' so that situations not specifically trained for can be handled successfully. This implies that skill application in both anticipated and unanticipated contexts is required, 
therefore a mix of both Conservative and Liberal approaches to instructional design is also required. In this way, 'transfer of training' provides a basis for the reconciliation of these two fundamentally different approaches to the design of instruction.

An 'Incremental-Transfer Skills Learning Model', based upon the above mentioned reconciliation, has recently been developed at Curtin University of Technology (Wallace, 1991). The use of this model as a basis for the design of computer-assisted instructional simulation will be trialed in late 1991.

\section{Conclusion}

A thorough treatment of conservative approaches to instructional design is an essential element in courses such as Victoria College's Graduate Diploma in Instructional Design and Technology. There is a solid basis in both theory and empirical evidence for practices involved in these approaches.

There is also considerable theory and empirical evidence to support many liberal approaches; consequently, these should also be addressed in instructional design courses. This should not be viewed as a contradiction to the validity of conservative approaches, but as an opportunity for instruction to profit from appropriate use of both types of approach. In his proposal for a phenomenological approach, to be combined with a systems approach, to training in the US military, Klein expressed this point well "... it is shortsighted to assume that any theoretical framework can be sufficient. It is more effective to understand a variety of frameworks, and to be able to apply the one most appropriate for any given task". (1977)

The concepts of 'near' and 'far' transfer of training may provide a useful basis for the selection and adaptation of specific instructional design principles and theories to local circumstances. Whatever approaches are eventually used, their selection should be based upon a thorough understanding of instructional design principles and not reliance upon acquired or imposed dogma.

\section{References}

Anderson, J. R (1980). Cognitive Psychology and its Implications. San Francisco: W.H. Freeman and Company.

Anderson, J. R. (1982). Acquisition of cognitive skin. Psychological Review, 89, 369406.

Anderson, J. R. (1985). Skill Acquisition: Compilation of Weak-Method Problem Solutions, (Report No. ONR-85-1). Pittsburgh, PA: Carnegie-Mellon University, Department of Psychology. (ERIC Document Reproduction Service No. ED 264 257). 
Bonner, J. (1988). Implications of Cognitive Theory for Instructional Design. Educational Communication and Technology Journal, 36, 3-14.

Bowen, J. \& Hobson, P. R (1974). Theories of Education. Brisbane: John Wiley \& Sons.

Clark, R. E. \& Voogel, R. (1985). Transfer of training principles. Educational Communication and Technology Journal, 33, 113-123.

De Bono, E. (1985). The CORT thinking program. In J. W. Segal, S. F. Chipman, \& R. Glasser (Eds.), Thinking and Learning Skills: Relating Instruction to Basic Research Vol 1, Hillsdale, NJ: Lawrence Erlbaum Associates.

Eddowes, E. E. (1974). A Cognitive Model of What is Learned During Flying Training, (Tech. Rep. No. AFHRL-TR-74-63). Brooks Air Force Base, Texas: Air Force Human Resources Laboratory.

Fitts, P. M. (1964). Perceptual-motor skill learning. In A. W. Melton (Ed.), Categories of Human Learning, New York, NY: Academic Press.

Fosnot, C. T. (1984). Media and Technology in Education: A Constructivist View. Educational Communication and Technology Journal, 32, 195-205.

Glencross, D. (1976). Acquisition of skill. Sports Coaching: Proceedings of a National Seminar. Canberra, ACT: Australian Government Publishing Service. (pp.22-29).

Jonassen, D. H. (1985). Learning Strategies: A New Educational Technology. Programmed Learning and Educational Technology, 22(1), 26-34.

Klein, G. A. (1977). Phenomenological Approach to Training. (Tech. Rep. AFHRL-TR77-42). Wright-Patterson Air Force Base, Ariz: Air Force Human Resources Laboratory.

Lane, N. E. (1987). Skill Acquisition Rates and Patterns. New York: Springer Verlag.

Miller, R. M., Swink, J. R. \& McKenzie, J. F. (1978). Instructional Systems Development (ISD) in Air Force Flying Training, (Tech. Rep. No. AFHRL-TR-7859). Brooks Air Force Base, Texas: Air Force Human Resources Laboratory.

Pearn, M. \& Downs, S. (1989). Developing skilled learners: a strategy for coping with new technology. Industrial and Commercial Training, 21(3).

Sahakian, W. S. (1976). Learning: Systems, Models and Theories. Chicago: Rand McNally College Publishing Company.

Strain, J. H. \& Inglis, A. (1990). What's in a name! that which we call a course by any other name would smell as sweet. Australian Journal of Educational Technology, 6(1), 1-11. http: / / www.ascilite.org.au/ajet/ajet6/strain.html

Wallace, P. R. (1991). An Incremental-Transfer Skills Learning Model. Unpublished manuscript, Curtin University of Technology, Faculty of Education, Perth, WA.

Author: Phil Wallace is a Squadron Leader in the Education Officer category of the Royal Australian Air Force. During 1991 he was conducting a study into the design of computer-assisted instructional simulation under the auspices of a Defence Force Fellowship. This Fellowship is being undertaken within the Education Faculty of Curtin University of Technology. From January 1992, correspondence may be addressed C/ HQTC, RAAF Williams, Point Cook, VIC 3029.

Please cite as: Wallace, P. R. (1992). A proposed reconciliation of conservative and liberal approaches to instructional design. Australian Journal of Educational Technology, 8(1), 13-26. http: / / www.ascilite.org.au/ajet/ajet8/wallace.html 